\title{
Study the Impact on Pension Liabilities as the Age of Retirement Increases
}

\author{
Rose Irnawaty Ibrahim and Zailan Siri
}

\begin{abstract}
Many proposals to solve the Government Pension Scheme's financial problems have suggested that the retirement age should be increased because the life expectancies are much higher today. Obviously, we knew that the pension liabilities of the Government Pension Scheme will be decreased as the retirement age increases. The objective of the study is to evaluate the impact on the pension liabilities to the government as the age of retirement increases. The pension liabilities were estimated using the closed group approach by estimating the capitalised future lifetime costs as the age of retirement increases from 55 to 60 years in phases of one year with an option to retire earlier. In order to estimate the capitalised future lifetime costs, we have to estimate the expected number of pensioners who survive, become disabled or die during their waiting time by constructing the multiple-decrement table. The empirical data sets of government employees who retired at age 55 in Malaysia for period of 1991 to 2000 will be considered in the study. It was found that increasing the retirement age will give favorable implications of the Government Pension Scheme in the long term. As a suggestion, the Government Pension Scheme should consider increasing the retirement age in the future in order to reduce their costs.
\end{abstract}

Index Terms-Pension liabilities, closed group approach, capitalised future lifetime costs, multiple-decrement table.

\section{INTRODUCTION}

Most contemporary research indicates that life expectancy in most countries is increasing. Since the average life expectancy tends to increase over time for males and females, the mortality risk tends to be smaller over time. Therefore, it is expected that pensioners will live longer and result in an increase in the pension liabilities of the government. In addition, due to medical advancement, better standard of living and working conditions, people are expected to live longer. Thus, with the present age of retirement, people are expected to have a longer retirement period than their working period. The implication is that the government will have to support pensioners for longer periods during their retirement. This would certainly increase the financial burden of the government.

However, there are several reasons gave by other countries to increase the retirement age such as because of the

Manuscript received April 30, 2013; revised July 1, 2013. This work was supported by the Ministry of Higher Education under Fundemental Research Grant Scheme (Grant No.: FRGS/1/2011/SG/USIM/02/3) and Universiti Sains Islam Malaysia.

R. I. Ibrahim is with the Faculty of Science and Technology, Universiti Sains Islam Malaysia, 71800 Bandar Baru Nilai, Negeri Sembilan, Malaysia (e-mail: rose.irnawaty@usim.edu.my).

Z. Siri was with Institute of Mathematical Sciences, University of Malaya, 50603 Kuala Lumpur, Malaysia (e-mail: zailansiri@um.edu.my). improvement in the life expectancy and improvement in the life expectancy at birth. Besides that, because of the social reason such as youngsters study for more years and they are dependent on their parents for a longer period. Thus, many family budgets get strained today because the main breadwinner retires before the next generation is settled in life. In addition, the other reason is because of an upward revision in the retirement age by several developed and developing countries. Also, there are financial advantages as well because an increase in the retirement age will reduce the impact of the annual pension payout liability for the government for at least the period by which the retirement age is raised.

In this study, we want to evaluate how much or how many percent the pension liabilities of the Government Pension Scheme will be decreased as the retirement age increases. Therefore, the main objective of the study is to evaluate the impact on pension liabilities to the government as the age of retirement increases from 55 to 60 years in phases of one year with an option to retire earlier. The study is based on the Malaysian Pension Schemes and thus the data collected is from the Pension Department, Public Service Department, Malaysia.

\section{LITERATURE REVIEW}

Even though the idea of pension liabilities is straightforward, the subject is often still confusing to researchers since there are numerous definitions and measures of pension liabilities for several types of pension schemes, and these are used for various evaluation purposes. This section aims to review a number of approaches in the literature to see how the size of pension liabilities is estimated, both in developed and developing countries, and what policy options should be selected to mitigate these liabilities and to achieve a just generational balance. In the context of pay-as-you-go (PAYG) pension schemes, studies have focused on three popular types, namely the open system approach, the closed group approach and the accrued to date approach.

The open system approach measures the present value of liabilities to current pensioners, current contributors, and people who have not yet entered the labour market (including children and the not yet-born population). The present value of all estimated future pension payments including those of new entrants is compared with present assets. If the contribution rate is set at the new entrant rate, the relationship between assets and liabilities of the open system and the closed system are exactly the same (as the net present value 
for new entrants would be zero).

The closed group approach estimates the present value of pension liabilities to current pensioners and contributors by assuming that the pension scheme exists until the youngest contributor dies, with no new entrants. The earliest comparative study of the impact of ageing on public pension liabilities, conducted in four Organisations for Economic Co-operation and Development (OECD) countries (Germany, Japan, Sweden, and the United States), was carried out by [1]. The authors measured unfunded public pension obligations by a closed-group approach. To avoid the ageing problems, they proposed alternative policy options such as accumulating funds that would balance revenues and expenditure, raising the retirement age, and reducing benefits. [2] also used a closed-group approach in estimating pension debts for 20 countries in Latin America. Their results are calibrated, the discount rate being equal to wage growth rate, indicating that the liabilities are severe even in countries with young populations and low coverage rates. [3], [4] also apply a unified methodology and assumptions to this issue, comparing estimates for 26 countries in the former study, and 35 countries in the latter study. Applying the closed-group approach, the authors estimate debts in various years during the late 1990s and 2000 with discount rates of 2, 4, and 5 percent. Their estimates vary between countries, and indicate that countries with swift demographic transitions and a long history of PAYG pension schemes will face the most serious problems. Finally, [5] used a closed-group approach in estimating pension liabilities, by applying the estimation methods of [6]. He assumed initially that disability and survivor pensions, and the practice of using different rules for males and females, are not considered. In the study, research was carried out using a closed-group approach.

The accrued to date approach calculates the present value of future pensions to be paid on the basis of accrued rights, with further contributions of current contributors and the accrual of new entrants not considered. This method computes the present value at the date of calculation of pensions to be paid in the future on the basis of accrued rights. It does not take account of possible new obligations or future income from contributions. This present value is then compared with the value of the fund's assets to see if minimum funding requirements are satisfied.

\section{Methodology}

The past raw data on pensioners were collected from the Pension Department, Public Service Department, Malaysia. The referred set was from year 1991 to 2000 and the information extracted included date of birth, date of entry to the scheme, date of retirement, date of death, gender, final monthly basic salary and also information on their dependants such as date of birth, status and gender. Adjustment was made whereby persons with unknown date of birth, date of entry to the scheme, date of retirement, date of death, sex and final monthly basic salary were excluded from the data. In the study, we only focused on government employees who retired at age 55 .

In order to evaluate the impact on the pension liabilities to the government as the age of retirement increases, it is important to estimate the capitalised future lifetime costs as the age of retirement increases from 55 to 60 years in phases of one year with an option to retire earlier in the year 1991 to 2000 for both males and females. As we know, the pension liabilities to the government are mainly the pension payments itself and the gratuities payable to its employees. In the study, the pension liabilities were estimated using the closed group approach.

In the calculation of the capitalised future lifetime costs, the concept of time value of money is necessary. Actuaries use this concept, together with the concept of probability, in the calculation of actuarial present values. The procession makes very wide use of the concept of "present value", in which money flows are "discounted", which is valued in a current frame by making explicit the time value of money. Although the rates of interest that money will earn in the future are not known, problems in compound interest can be solved by making assumptions as to the future rate of interest. Once the assumptions are made, numerical results are obtained with the aid of tables containing functions such as $(1+i)^{-k}, v^{k}$. Assuming the valuation is done on $1^{\text {st }} \mathrm{Jan}$ of the particular year that we are considering, the model to estimate the capitalised future lifetime costs for pensioners who retired at age 55 years can be written as

$$
C_{t}^{55}=\sum_{i=1}^{N} v^{k} B_{i}^{55} L_{i}^{55}+v^{k} G_{i}^{55}
$$

where,

- $C_{t}^{55}=$ Capitalised future lifetime costs for pensioners who retired at age 55 years at a particular year $t$,

- $B_{i}^{55}=$ The amount of annual pensions payment for a particular pensioner $i$ who retired at age 55,

- $G_{i}^{55}=$ The amount of gratuity for a particular pensioner $i$ who retired at age 55 ,

- $L_{i}^{55}=$ The longevity factor or pension factor for a particular pensioner $i$ who retired at age 55,

- $t=$ year of study, which is year 1991 to 2000,

- $N=$ Total number of pensioners in a particular year $t$, and

- $k=$ Year to retire.

In the study, we assume that when a retirement age is considered, the option to retire earlier will be given like the existing pension law. For example, the retirement age is 56 years, the option is given for those who want to retire at age 55 years and we present it as $56^{*}$. If we increase the retirement age of 57 years, the options to retire are at ages 55 and 56 years and we present it as $57^{*}$. And if we increase the retirement age of 60 years, the options to retire are at ages 55 , $56,57,58$ and 59 years and we present it as $60^{*}$.

We also assume that for the group of pensioners who choose to retire later, some of them might die or become disabled during their waiting time. Thus, the decrement forces involved in the study are only death and disability. For $56^{*}$ or those who choose to retire at age 56 , some of them might die or become disabled at age 55. Thus for $C_{t}^{56^{*}}$, we have to estimate the capitalised future lifetime costs for:

- Those who choose the option to retire at age 55 [first line 
for $j=0$ in (2)],

- Those who choose to retire at age 56 [first line for $j=1$ in (2)],

- Those who choose to retire at age 56 and die at age 55 [second line in (2)], and

- Those who choose to retire at age 56 and are disabled at age 55 [third line in (2)].

Or we can write it in a mathematical model as follows:

$$
C_{t}^{56^{*}}=\sum_{i=1}^{N}\left\{\begin{array}{l}
\left(\sum_{j=0}^{1}\left[v^{k+j} B_{i}^{55+j} L_{i}^{55+j}+v^{k+j} G_{i}^{55+j}\right]\right)+ \\
\left(v^{k} B_{i_{d}}^{55} L_{i}^{d(55)}+v^{k} G_{i_{d}}^{55}\right)+ \\
\left(v^{k} B_{i_{d i s}}^{55} L_{i}^{d i s(55)}+v^{k} G_{i_{d i s}}^{55}\right)
\end{array}\right\}
$$

For $57^{*}$, those who choose to retire at age 57 ; some of them might die or become disabled at age 56 and for those who choose the option to retire at age 56, and some of them might die or become disabled at age 55 . Thus for $C_{t}^{57^{*}}$, we have to estimate the capitalised future lifetime costs for:

- Those who choose the option to retire at age 55 [first line for $j=0$ in (3)],

- Those who choose the option to retire at age 56 [first line for $j=1$ in (3)],

- Those who choose to retire at age 57 [first line for $j=2$ in (3)],

- Those who choose the option to retire at age 56 and die at age 55 [second line for $j=0$ in (3)], and

- Those who choose the option to retire at age 56 and are disabled at age 55 [third line for $j=0$ in (3)],

- Those who choose to retire at age 57 and die at age 56 [second line for $j=1$ in (3)], and

- Those who choose to retire at age 57 and are disabled at age 56 [third line for $j=1$ in (3)].

In a mathematical model can be written as:

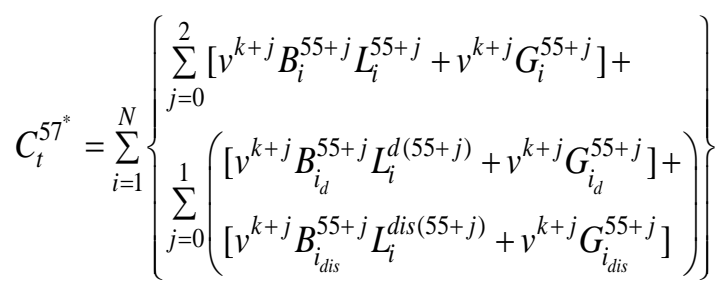

Similarly, for $C_{t}^{58^{*}}, C_{t}^{59^{*}}$ and $C_{t}^{60^{*}}$, we can written as:

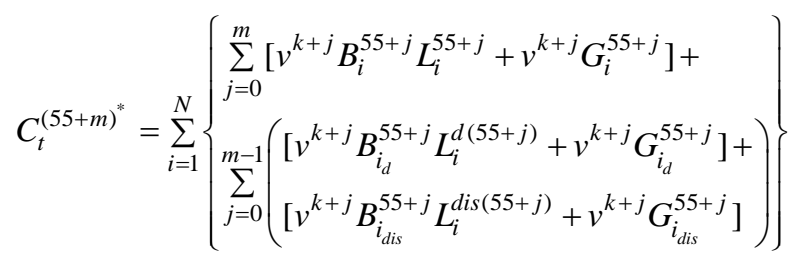

where, $m=3,4,5$ for $58^{*}, 59^{*}$ and $60^{*}$ respectively.

Referring to [7], the formulae for yearly pension and gratuity for a particular pensioner $i$ who survives, dies and becomes disabled at age $x$ are given as:

$$
B_{i}^{x}, B_{i_{d}}^{x} \text { and } B_{i_{d i s}}^{x}= \begin{cases}12 \times \frac{1}{600} \times S_{i} \times M_{i}^{x}, & \text { for } M_{i}^{x} \leq 300 \\ 12 \times \frac{1}{2} \times S_{i}, & \text { for } M_{i}^{x}>300\end{cases}
$$

and

$$
G_{i}^{x}, G_{i_{d}}^{x} \text { or } G_{i_{d i s}}^{x}=0.075 \times S_{i} \times M_{i}^{x}
$$

where,

- $S_{i}=$ The final basic monthly salary for a particular pensioner $i$;

- $\quad M_{i}^{x}=$ Total completed months of reckonable service for a particular pensioner $i$ who chooses to retire at age $x$.

The description for $L_{i}^{x}$ and $L_{i}^{d(x)}$ can be found in [8] and

[9], while $L_{i}^{\text {dis(x) }}$ is calculated using the disability rates from [10].

In order to estimate the $C_{t}^{x^{*}}$, we have to estimate the expected number of pensioners who survive, become disabled or die during their waiting time by constructing the multiple-decrement table. In the study, we evaluate a pension scheme where there are two causes of decrement, which are death and disability. We assume that the number of these pensioners forms a closed group. So, there should be no new entrants and also no re-entrants after retirement. Thus in the study, a double-decrement table will be constructed. This double-decrement table is used to find the decrement rate of death and permanent disability (independent rates) and will be distinguished to the probability of death and permanent disability (dependent rates).

The mortality rates, ' $q_{x}^{\prime}$ ' [11] and [12] are used as the independent rates for death and we denote it as $q_{x}^{d}$. Since we do not have data on permanent disability rates because the incidence of disability is relatively small amongst most populations, we use the data on Pension Fund Tables from [10] (where $i_{x}$ is dependent). Then, we must convert it to the independent rates for permanent disability and we denote it as $q_{x}^{i}$. In this calculation, we will use the independent rates $\left[q_{x}^{d}, q_{x}^{i}\right]$ and find the dependent rates of death $\left[(a q)_{x}^{d}\right]$ and permanent disability $\left[(a q)_{x}^{i}\right]$ by putting those rates into these two equations:

$$
(a q)_{x}^{d} \doteqdot \frac{q_{x}^{d}\left(1-\frac{1}{2} q_{x}^{i}\right)}{1-\frac{1}{4} q_{x}^{d} q_{x}^{i}} \text { and }(a q)_{x}^{i} \doteqdot \frac{q_{x}^{i}\left(1-\frac{1}{2} q_{x}^{d}\right)}{1-\frac{1}{4} q_{x}^{d} q_{x}^{i}}
$$

where;

- $\quad(a q)_{x}^{d}=$ The probability that a pensioner aged $x$ will die between exact age $x$ to exact age $x+1$, 
- $(a q)_{x}^{i}=$ The probability that a pensioner aged $x$ will become disabled between exact age $x$ to exact age $x+1$.

After these rates have been computed, the double-decrement table can be constructed. The dependent rates of death and permanent disability for male and female are computed separately. In constructing double-decrement table, the radix $(a l)_{x}$ is assumed to be the total number of pensioners who retire at age 55 in a particular year $t$. Hence, the expected number of deaths and permanent disability can be evaluated by establishing the value of $(a l)_{x}$, $(a d)_{x}^{d}$ and $(a d)_{x}^{i}$. The assumptions and formulae used are as follows:

$$
(a d)_{x}^{d}=(a q)_{x}^{d} \times(a l)_{x} \text { and }(a d)_{x}^{i}=(a q)_{x}^{i} \times(a l)_{x}
$$

where,

- $(a l)_{x}=$ the total expected number of pensioners who survive at exact age $x$,

- $\quad(a d)_{x}^{d}=$ the total expected number of pensioners dying between exact age $x$ to exact age $x+1$,

- $(a d)_{x}^{i}=$ the total expected number of pensioners who become disabled between exact age $x$ to exact age $x+1$.

Once we have the $(a l)_{x},(a d)_{x}^{d}$ and $(a d)_{x}^{i}$, we can simulate the random number to justify randomly the number of pensioners will survive, become disabled and die during their waiting time. But before we simulate the random number, we give an identity number for each pensioner, which is firstly we sort all the pensioners according to their final basic monthly salary (smaller to higher). In the study, we develop the program to simulate the random number using Microsoft Visual C++ 6.0 software. When we have justified randomly the number of pensioner will survive, become disabled and die, we have been able to compute the amount of yearly pension and gratuity for a particular pensioner $i$ who survives, dies and becomes disabled.

For a given cohort of pensioners, we expect that for an increase in $x^{*}$, the $C_{t}^{x^{*}}$ will be decreased. From (1) to (4), there are two factors involved in the model. The first is the increasing factors, which is an increase in gratuity benefits of an increase in $x^{*}$. And the other is the decreasing factors, which is a decrease in the span of pension payments for an increase in $x^{*}$. However, we expect the decreasing factors to be much greater.

\section{NUMERICAL RESUlTS AND DISCUSSION}

In the study, the financial analysis of percentage reduction in estimated capitalised future lifetime costs as the age of compulsory retirement increases from 55 to 60 years in the phase of one year with an option to retire earlier in the year 1991 to 2000 for both male and female is also evaluated. The percentage reduction in estimated capitalised future lifetime costs as the $x^{*}$ increases in year $t$ can be evaluated by

$$
P R_{t}^{x^{*}}=\left(\frac{C_{t}^{55}-\mathrm{C}_{t}^{x^{*}}}{C_{t}^{55}}\right) \times 100
$$

where,

- $P R_{t}^{x^{*}}=$ percentage reduction in capitalised future life-time costs for $x^{*}$ at a particular year $t$,

- $C_{t}^{55}=$ total capitalised future lifetime costs using retirement age 55 as the base, at a particular year $t$,

- $C_{t}^{x^{*}}=$ total capitalised future lifetime cost for $x^{*}$ at a particular year $t$.

TABLE I: SUMmary of $P R_{t}^{x^{*}}$ AND AVERAGe $P R_{t}^{x^{*}}$

\begin{tabular}{|c||c|c|c|c|c|}
\hline $\begin{array}{c}\text { Year, } \\
\boldsymbol{t}\end{array}$ & $P R_{t}^{56^{*}}$ & $P R_{t}^{57^{*}}$ & $P R_{t}^{58^{*}}$ & $P R_{t}^{59^{*}}$ & $P R_{t}^{60^{*}}$ \\
\hline \hline $\mathbf{1 9 9 1}$ & 3.39 & 5.95 & 8.18 & 10.17 & 11.90 \\
\hline $\mathbf{1 9 9 2}$ & 3.36 & 5.90 & 8.12 & 10.07 & 11.78 \\
\hline $\mathbf{1 9 9 3}$ & 3.44 & 6.00 & 8.26 & 10.25 & 12.00 \\
\hline $\mathbf{1 9 9 4}$ & 3.50 & 6.14 & 8.45 & 10.50 & 12.28 \\
\hline $\mathbf{1 9 9 5}$ & 3.56 & 6.23 & 8.58 & 10.73 & 12.49 \\
\hline $\mathbf{1 9 9 6}$ & 3.55 & 6.25 & 8.62 & 10.71 & 12.54 \\
\hline $\mathbf{1 9 9 7}$ & 3.55 & 6.25 & 8.64 & 10.75 & 12.57 \\
\hline $\mathbf{1 9 9 8}$ & 3.60 & 6.30 & 8.68 & 10.77 & 12.60 \\
\hline $\mathbf{1 9 9 9}$ & 3.62 & 6.35 & 8.78 & 10.92 & 12.79 \\
\hline $\mathbf{2 0 0 0}$ & 3.64 & 6.37 & 8.78 & 10.91 & 12.75 \\
\hline \hline $\mathbf{A v g}$ & 3.52 & 6.17 & 8.51 & 10.58 & 12.37 \\
\hline
\end{tabular}

Table I show that the percentage reduction in estimated capitalised future lifetime costs increases as retirement age increases. This is because the values of $C_{t}^{x^{*}}$ are decreased as retirement age increases. Also the average percentage reduction in estimated capitalised future lifetime costs for year 1991 to 2000 when $56^{*}, 57^{*}, 58^{*}, 59^{*}$ and $60^{*}$ are considered are $3.52 \%, 6.17 \%, 8.51 \%, 10.58 \%$ and $12.37 \%$ respectively. In other words, we can say that the pension liabilities to the Government Pension Scheme are reduced around $3.52 \%, 6.17 \%, 8.51 \%, 10.58 \%$ and $12.37 \%$ respectively when $56^{*}, 57^{*}, 58^{*}, 59^{*}$ and $60^{*}$ are considered. Thus, if we want more reduction in pension liabilities in the future, we should consider increasing in the retirement age for a few more years. For example, increasing the retirement age by 5 years from 55 to 60 would be similar to a proposal of decreasing retirement benefits by about $12.37 \%$. However, the results shows that the values of $P R_{t}^{x^{*}}$ are positive during period of study, meaning that the pension liabilities to the Government Pension Scheme always reduce as retirement age increases.

From Table II, we found that the difference in average percentage reduction in estimated capitalised future lifetime costs between an increase of 1 year and 2 years is around $2.65 \%$. And the differences in average percentage reduction in estimated capitalised future lifetime costs between an increase of 1 year and 3 years, 1 year and 4 years, 1 year and 5 years are $4.99 \%, 7.06 \%$ and $8.85 \%$ respectively. However, if we made comparisons between an increase in 2 years and 3 years, 2 years and 4 years and 2 years and 5 years, we found that the differences in average percentage reduction in estimated capitalised future lifetime costs are $2.34 \%, 4.41 \%$ and $6.2 \%$ respectively. And the differences in average percentage reduction in estimated capitalised future lifetime costs between an increase of 3 years and 4 years, 3 years and 
5 years and 4 years and 5 years are $2.07 \%, 3.86 \%$ and $1.79 \%$ respectively. Therefore, we can conclude that if we increased more in retirement age, the better would be the percentage reduction in estimated capitalised future lifetime costs.

TABLE II: SUMmARy OF PERCENTAGE DIFFERENCE IN AVERAGE $P R_{t}^{x^{*}}$ FOR SEVERAL CASES OF INCREASE IN YeAR OF RETIREMENT AGE

\begin{tabular}{|c|c|c|c|c|}
\hline $\begin{array}{c}\text { Difference } \\
\text { (in \%) }\end{array}$ & $\mathbf{1}$ & $\mathbf{2}$ & $\mathbf{3}$ & $\mathbf{4}$ \\
\hline \hline 1 & - & - & - & - \\
\hline 2 & 2.65 & - & - & - \\
\hline 3 & 4.99 & 2.34 & - & - \\
\hline 4 & 7.06 & 4.41 & 2.07 & - \\
\hline 5 & 8.85 & 6.20 & 3.86 & 1.79 \\
\hline
\end{tabular}

Therefore, to decrease the pension liabilities as the total number of pensioners increased year by year, we need to increase the retirement age. Thus, if we want more reduction in pension liabilities in the future, we shall consider a greater increase in the retirement age. As a conclusion, increased in retirement age will give favorable implications of the Pension Scheme because the costs to the Government Pension Scheme in the long term are reduced when the retirement age increases. Thus, the Government Pension Scheme should consider increasing the retirement age in the future in order to reduce their costs.

\section{ACKNOWLEDGMENT}

R. I. Ibrahim thanks to Ministry of Higher Education, Malaysia and Universiti Sains Islam Malaysia for their financial support (FRGS/1/2011/SG/USIM/02/3). Z. Siri would like to thanks University of Malaya for equipment provided.

\section{REFERENCES}

[1] R. P. Hagemann and G. Nicolleti, "Ageing populations: economic effects and implications for public finance," OECD Department of Economics and Statistics, Working Paper, no. 61, 1989.

[2] J. Bravo and A. Uthoff, "Transitional costs and demographic factors in shifting from unfunded to funded pension scheme in Latin America," Development Finance Unit, Latin American and Caribbean Demographic Center, Chile, Technical Paper, 1999.

[3] R. Holzmann, R. Palacios, and A. Zviniene, "Implicit pension debt: issues, measurement, and scope in the international perpectives," Social Protection Department, The World Bank, Technical Paper, 2001.

[4] R. Holzmann, R. Palacios, and A. Zviniene, "Implicit pension debt: issues, measurement, and scope in the international perspectives," Social Protection Department, The World Bank, Working Paper, no. 0403, 2004.

[5] T. L. Giang, "Pension liabilities and generational relations: the case of Vietnam," Munich Personal Repec, Archive Paper, no. 970, 2005.

[6] D. Franco, M. R. Marino, and S. Zotteri, "Pension expenditure projections, pension piabilities, and European Union Fiscal Rules,"
International Workshop on the Balance Sheet of Social Security Pensions, Hitotsubashi University, Tokyo, no. 1-2, 2004.

[7] International Law Book Services, Pension Laws of Malaysia, Direct Art Company, Kuala Lumpur, 2001.

[8] R. I. Ibrahim, "Impact of increasing retirement age on longevity factor: An empirical study for government pensioners in Malaysia," Journal Ekonomi Malaysia, vol. 46, no. 2, pp. 29-35, 2012.

[9] R. I. Ibrahim and Z. Siri, "A study on longevity factors for the new and old government pension policies in Malaysia," Malaysian Journal of Economic Studies, vol. 49, no. 2, pp. 111-119, 2012.

[10] A. Neill, Life Contingencies, William-Heinemann Ltd. London, 1977.

[11] R. I. Ibrahim, "Expanding an abridged life table using the Heligman-Pollard model," Matematika, vol. 24, pp. 1-10, 2008.

[12] R. I. Ibrahim and Z. Siri, "Methods of expanding an abridged life tables: comparison between two methods," Sains Malaysiana, vol. 40, no. 12, pp. 1449-1453, 2011.

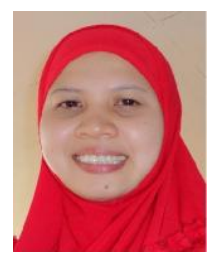

Rose Irnawaty Ibrahim was born in Kuala Lumpur, Malaysia, in 1976. She received the B.Sc. in Computational and Industrial Mathematics from the University of Malaya, Malaysia, in 2000, and the M.Sc. in Actuarial Science from the Heriot-Watt University, U.K. in 2001. Then, she received Ph.D. in Actuarial Science from Universiti Teknologi Mara, Malaysia, in 2009. In 2001, she joined the Institute of Mathematical Sciences, University of Malaya, as a tutor, and in 2006 became a lecturer. In February 2011, she joined the Faculty of Sciences and Technology, Universiti Sains Islam Malaysia as a senior lecturer. The latest publications are R. I. Ibrahim and Z. Siri, "Methods of expanding an abridged life tables: comparison between two methods," Sains Malaysiana, vol. 40(12), pp. 1449-1453, 2011., R. I. Ibrahim, "Impact of increasing retirement age on longevity factor: an empirical study for government pensioners in Malaysia," Jurnal Ekonomi Malaysia, vol. 46(2), pp. 29-35, 2012. and R. I. Ibrahim and Z. Siri, "A study on longevity factors for the new and old government pension policies in Malaysia," Malaysian Journal of Economic Studies, vol. 49(2), pp. 111-119, 2012. Her current research interests include Mortality Study and Pension Scheme, Survival Analysis, Fuzzy and Computational Mathematics. Dr. Ibrahim was a memberships of Malaysia Institute of Statictics in 2007 until 2008 and a memberships of Malaysian Mathematical Sciences Society and Golden Key Society Malaysia for life.

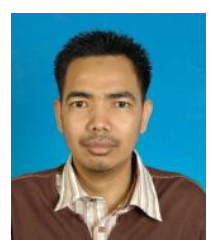

Zailan Siri was born in Melaka, Malaysia, in 1977. He received the B.Sc. in Computational and Industrial Mathematics from the University of Malaya, Malaysia, in 2001, and the M.Sc. in Numerical Analysis from the Universiti Putra Malaysia, in 2004. Then, he received Ph.D. in Mathematics from Universiti Kebangsaan Malaysia in 2012. In 2002, he joined the Institute of Mathematical Sciences, University of Malaya, as a tutor, and in 2004 became a lecturer. Since July 2012, he has been with the Institute of Mathematical Sciences, University of Malaya, where he was a senior lecturer. The related publications are R. I. Ibrahim and Z. Siri, "Methods of expanding an abridged life tables: comparison between two methods," Sains Malaysiana, vol. 40(12), pp. 1449-1453, 2011. and R. I. Ibrahim and Z. Siri, "A study on longevity factors for the new and old government pension policies in Malaysia," Malaysian Journal of Economic Studies, vol. 49(2), pp. 111-119, 2012. His current research interests include Numerical Analysis, Fluids Flow Problems, Chaotic Convection, and Mortality Study and Pension Scheme. Dr. Siri was a memberships of Malaysian Mathematical Sciences Society and Golden Key Society Malaysia for life. 